\title{
Recent Advances in Combustion Technology for Heating Processes*
}

\author{
Masashi KATSUKI**
}

\begin{abstract}
Recent advancement in industrial furnaces brought by highly preheated air combustion is reviewed. Highly Preheated Air Combustion in regenerative furnaces has been paid much attention for its accomplishment in not only energy saving but also low nitric oxides emission. Characteristics of combustion with highly preheated air were studied to understand the change of combustion regime and the reason for the compatibility between high performance and low nitric oxides emission. It was found that combustion was sustained even in an extremely low concentration of oxygen if the temperature of oxidizer was higher than the auto-ignition temperature of the fuel. As an application of the principle, we can reduce nitric oxides emission by dilution of combustion air with plenty of recirculated burned gas in the furnace. Dilution makes the oxygen content of the oxidizer low, which decreases temperature fluctuations in flames as well as the mean temperature, hence low nitric oxides emission. Finally, the applicability of highly preheated air combustion to other fields than industrial furnaces has been discussed.
\end{abstract}

Key Words: Combustion, Furnace, Regenerative Furnace, Nitric Oxide, Fuel Saving, $\mathrm{CO}_{2}$ Reduction, Thermal Efficiency, Preheated Air

\section{Introduction}

Energy consumption is increasing in recent years not only in developed countries but also in developing countries primarily due to rapid industrialization and the change of life style. Since the large fraction of heat energy necessary for our daily life is mostly produced by combustion, the increased energy consumption has generated a direct impact on emission of carbon dioxide and nitrogen oxide into environment. As the energy and environmental issues have become one of the prime concerns of the mankind, the advancement of combustion technology plays an important role in resolving the problem.

From the 1960s through the beginning of the 1970s, we experienced two serious problems that gave strong influence on the direction of progress in combustion technologies. The first one was the issue of pollutant emissions generated by combustion, such as

* Received 3rd April, 2003 (No. 03-4037)

** Department of Mechanical Engineering, Osaka University, 2-1 Yamada-oka, Suita, Osaka 565-0871, Japan. E-mail : katsuki@mech.eng.osaka-u.ac.jp sulfur oxide $\left(\mathrm{SO}_{x}\right)$, nitrogen oxide $\left(\mathrm{NO}_{x}\right)$ and smog. The other was the requirement of efficient use of energy enforced by the oil-embargo.

In developed countries the problem of air pollution has been caused by the combustion exhaust emissions brought by the rapid expansion of industrial production and the remarkable prevalence of motorization in the private sector. It has become a serious social problem, so that regulations for restriction of pollutant emissions have been enforced. To cope with this requirement, each industry worked intensively on the development of combustion methods and control for low level of pollutant emissions, particularly nitric oxide.

In 1990's again, reduction of greenhouse gas started to be claimed, and the Kyoto Protocol (COP3) was issued in December 1997. Therefore, the reduction of carbon dioxide emissions became an urgent issue particularly in industries where a large amount of fossil fuels were consumed. Upon the background, a national project on development of advanced combustion technology, supported the Ministry of International Trade and Industry of Japan, was carried out aiming at significant reduction of energy consumption 
and contribution to the environmental preservation, simultaneously. However, high thermal efficiency and low nitric oxide emission had been believed a tradeoff issue, and resolution of these incompatible demands was the final goal of the project.

Consequently, a new concept of regenerative heating furnace has been developed, in which reduction of fuel consumption by approximately $30 \%$ and low nitric oxide emission sufficiently below the regulation were achieved. These epoch-making performances were brought by the entirely new combustion technology using highly preheated combustion air utilizing the recovered waste heat.

In this paper, we are going to discuss about the reason why nitric oxides emission can be decreased even by use of highly preheated combustion air, and how we can realize the new combustion regime in practical furnaces.

\section{Heat Recirculating Combustion}

Preheating of combustible mixture by the recycled heat from exhaust gases has been considered as an effective method for combustion of low caloric fuel or ultra-lean mixture. Many related researches were carried out in the past [e.g. Refs. (1) - (3)], and the concept of heat recirculating combustion was clearly demonstrated by Weinberg et al. ${ }^{(2)}$ in the famous Swiss-roll burner. A special feature of this method is that a heat source for preheating is not necessary to maintain ultra-lean combustion except during the time of start-up. Heat transfer from burned products to unburned mixture occurs through double-roll walls separating the products and the mixture. Figure 1 shows the temperature histories of premixed combustion with and without heat recirculation in an adiabatic system. If it were a complete adiabatic system, the outlet temperature of burned gas would be the same regardless heat recirculation. Adding to this fact, the maximum temperature level in heat recirculating combustion is determined by the temperature and amount of recycled heat, which is independent on the equivalence ratio of the mixture or the caloric

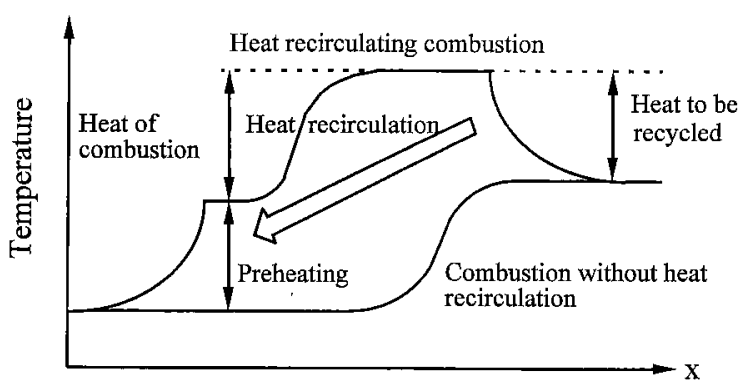

Fig. 1 Temperature history of premixed combustion with and without heat recirculation ${ }^{(1)}$ value of the fuel used. The concept is true for premixed combustion, but not always so for non-premixed or diffusion combustion in furnaces. This is the most important point when we consider about highly preheated air combustion stated later.

Excess enthalpy combustion studied in the past has been often intended to sustain stable combustion in the mixture of low caloric fuel or ultra-lean mixture that is far from flammable at atmospheric temperature. Therefore, combustion follows a temperature rise of mixture to an elevated level by heat recirculation ${ }^{(4)-(10)}$.

Figure 2 shows the combustible domain expressed in terms of equivalence ratio, caloric value of fuel and mixture temperature, respectively ${ }^{(11)}$. At normal ambient temperature, an ordinary hydrocarbon gaseous fuel mixed with atmospheric air exhibits a combustible domain around the stoichiometric composition, and an increase of temperature of mixture expands the combustible domain significantly. If we want to use a low caloric fuel, in contrast, the combustible domain disappears at ambient temperature and starts to reappear when the mixture is preheated up to a certain temperature level. Thus, we can understand that the excess enthalpy combustion of low caloric value fuel or ultra-lean mixture is a method to bring the mixture from outside of the combustible domain into the inside by heat recirculation.

Combustion efficiency is sufficiently high in most of practical furnaces, but the efficiency of heat utilization is not always high. To raise the thermal efficiency of industrial furnaces, such as melting furnaces or reheating furnaces, the heat recirculation from high temperature waste gas to the fresh combustion air has been a typical measure, because diffusion or non-premixed combustion is more common in those furnaces. It has been realized with a heat exchanger or a recuperator to recover the waste heat. Therefore, the combustion with preheated air is not

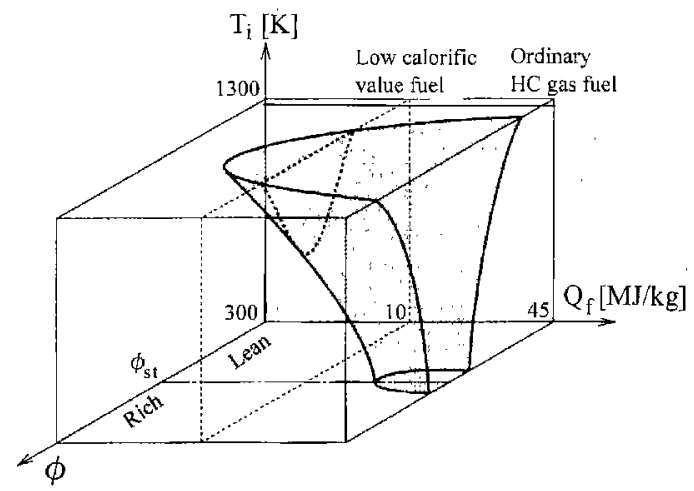

Fig. 2 Flammable domain as a function of calorific value of fuel, initial temperature of mixture and mixture and mixture equivalence ratio ${ }^{(10)}$ 


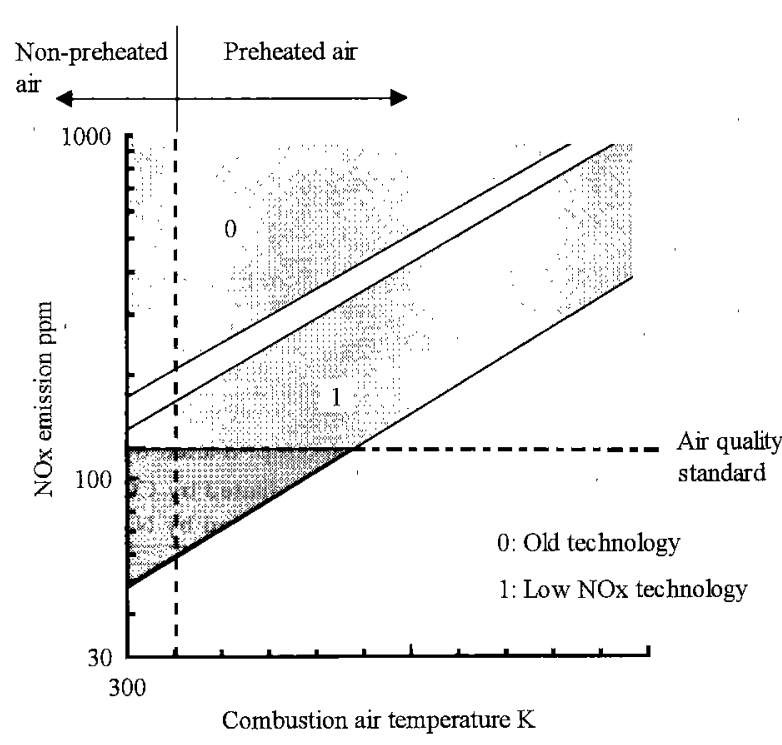

Fig. 3 Correlation between combustion air temperature and nitric oxide emission ${ }^{(28)}$

new as a technology or a concept to save energy. A recuperator was mostly used in large-scale industrial furnaces as a waste heat recovery unit, by which the temperature of preheated air was raised about 600 to $700^{\circ} \mathrm{C}$ at most due to the durability of its material $^{(12),(13)}$.

It has been held that combustion reaction takes place near-stoichiometric during the mixing process between fuel and air even in high excess air ratio nonpremixed combustion, and thus the near-stoichiometric flame temperature of preheated combustion causes intolerable nitric oxides emission. Therefore, as exemplified in Fig. 3, we are obliged to stop preheat of air so that the nitric oxides emission does not violate air quality regulations even though more energy saving is expected by higher preheating. If the regulation for nitric oxides becomes stricter, the consistency of energy saving by heat recirculation and low nitric oxides emission would be more difficult. Therefore, the development of low nitric oxide combustion technology using non-premixed flame would be one of the most important subjects in the heat regenerative combustion.

Many researches and efforts have been made to satisfy these two incompatible requirements simultaneously ${ }^{(14)-(20)}$. Among them, a high-frequency alternating flow regenerative furnace, the basic concept of which is illustrated in Fig. 4, is one of the most successful systems in which remarkable energy saving can be achieved without emitting high concentration of nitric oxides ${ }^{(21),(22)}$. The system consists of two sets of a ceramic honeycomb regenerator and a burner. Since they are operated alternatively every minute or so, extremely high heat exchange coefficient is

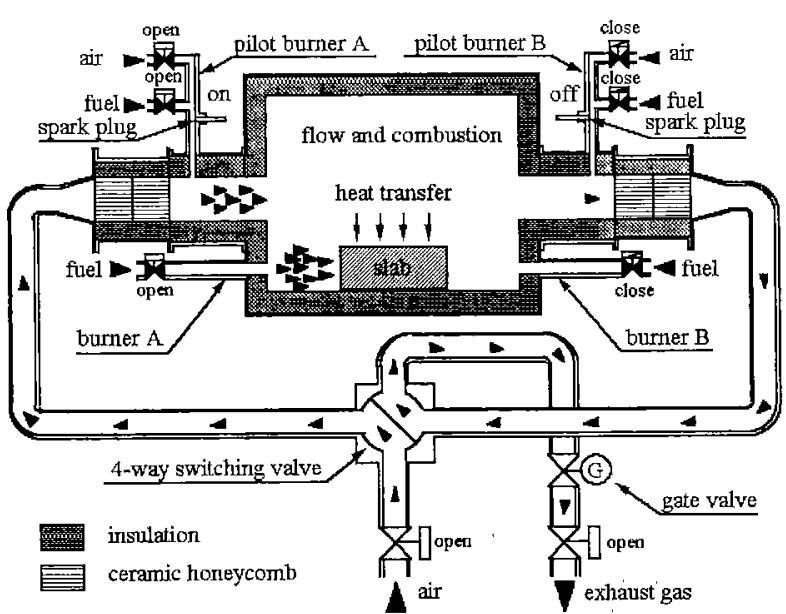

Fig. 4 Schematic structure of heating furnace operated with high frequency alternating flow regenerators $^{(21)}$

achieved by the effect of unsteady heat transfer in the honeycomb regenerator, where the flow direction of exhaust gas and fresh air alternates against each other.

\section{Regenerator}

Preheat of combustion air depends not only on the tolerance of materials used, such as heat-resistance alloy and refractory but also on heat losses of the system. Accordingly, the higher the maximum temperature of combustion air and the lower the final waste temperature of exhaust are, the better performance of a regenerator is obtained. The alternating flows of outgoing exhaust and incoming combustion air through the regenerator realizes higher heat transfer efficiency than the steady-flow type heat exchanger, such as recuperator. The typical regenerator for preheat of combustion air was a bed in a container packed with ceramic balls. Its size varies depending on the cycle time, that is, the amount of heat storage.

The volume of a honeycomb type regenerator for the necessary heat capacity can be minimized because of its large surface to volume ratio, and thereby direct installation of regenerator into a burner becomes possible. Almost constant temperature of combustion air, less than $50 \mathrm{~K}$ variation during a cycle, was realized in the following procedure even with the small heat capacity of regenerator.

In Fig. 5 temperature profiles in ceramic honeycombs along the flow direction at both start and end of discharge mode of the regenerator are schematically illustrated. The amount of heat between two limiting profiles in the figure is available for heat recirculation during a cycle. One can anticipate that the temperature of preheated air can be kept almost constant during a cycle from the fact that the temperature 


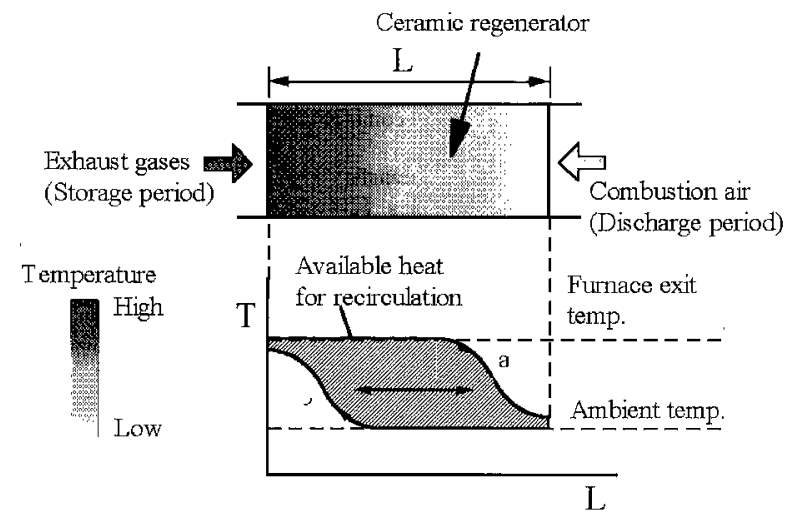

Fig. 5 Change of temperature profile and available heat in a honeycomb regenerator (schematic)

change on furnace side is small. Besides, the length of the ceramic honeycombs should be selected so that the temperature at the ambient side does not rise so much in order to keep the heat loss rejected with exhaust gases minimized.

In practice, we can preheat the combustion air up to within $100 \mathrm{~K}$ of the exhaust gas temperature resulting in sufficiently low temperature of the outgoing exhaust gas. Therefore, preheated air higher than $1273 \mathrm{~K}$ can be easily obtained compared to other types of heat recovery device, and this fact suppresses the heat loss in the exhaust. We did not consider in the past that the utilization of such high temperature combustion air is consistent with the low nitric oxides emission technology.

\section{Auto-Ignition Temperature of Fuel}

When a fuel mixes with combustion air, some heat is necessary to initiate combustion. Therefore, a recirculating flow of combustion products behind a flame holder or a pilot flame is frequently utilized in furnace combustion to stabilize flames. However, if combustion air is sufficiently preheated, combustion follows immediately the mixing of two reactants anywhere in the furnace. Suppose combustion of natural gas with atmospheric air, auto-ignition will occur when the preheating temperature of air exceeds approximately $1100 \mathrm{~K}$, and for lower preheating temperatures, a forced ignition and a flame stabilizer will be necessary for stable combustion as in the ordinary furnaces.

Shown in Fig. 6, with the decrease of oxygen content by inert gas dilution, the auto-ignition limit in terms of air preheat temperature rises slightly but the forced-ignition limit rises significantly. In other words, as the air preheat temperature goes down, it becomes more difficult to stabilize flames in low oxygen circumstances. For the oxygen content lower than roughly $15 \%$ in the diluted air, the combustible

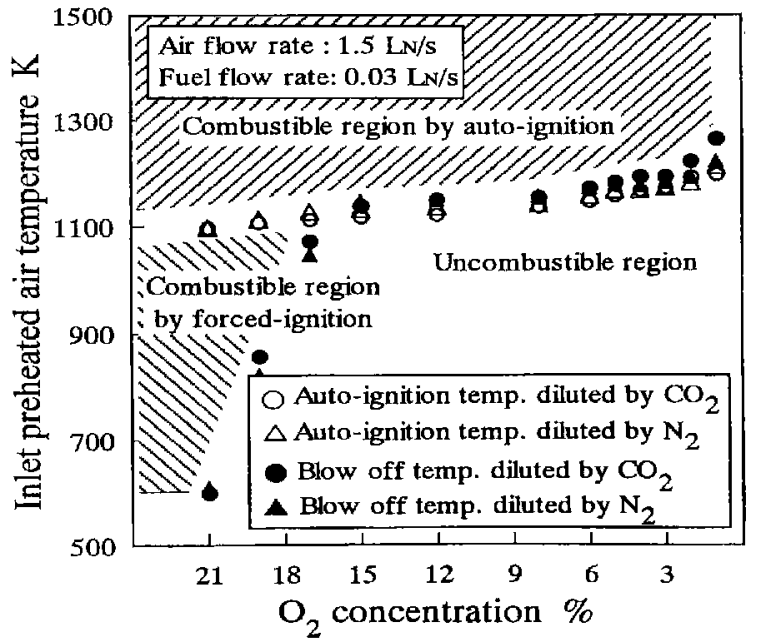

Fig. 6 Auto-ignition limits and blow ${ }^{-}$off limits for natural gas in a preheated air or its dilution ${ }^{(28)}$

region for forced-ignition disappears and only autoignition occurs when the diluted air is extremely preheated. From these experimental data we have obtained new knowledge on combustion characteristics of gaseous fuels under low oxygen content circumstances which had not been paid much attention from a practical point of view. The point is that we can burn out a gaseous fuel even in quite low oxygen content condition, such as vitiated or diluted air, if its temperature is sufficiently high.

Although too large amount of exhaust gas recirculation may cause flame extinction when we adopt ambient air as an oxidizer, the preheating of combustion air above the auto-ignition temperature of the fuel ensures complete combustion even with an intense exhaust gas recirculation. Therefore, we would like to call this type of combustion as highly preheated air combustion distinguishing from preheated air combustion, in which a conventional burner technology must be applied and auto-ignition does not occur. In contrast, any measure to stabilize a flame is not necessary in highly preheated air combustion.

\section{Flame Temperature}

Temperature of combustion products in adiabatic circumstances can easily be defined by the global excess air-ratio. However, heat transferred to materials to be heated in the furnace as well as heat losses exist in practical systems is influencing factors in defining gas temperature in the furnace. Adding to this fact, exhaust gas recycling, whether it is internal or external, is an effective method to reduce flame temperature, and thereby nitric oxide emission. Therefore, the reduced temperature level of burned gas as well as its recycling flow rate largely affects flame temperature associated with exhaust gas recy- 
cling.

Combustion with normal ambient air usually becomes unstable when the exhaust-recycling rate, defined as the mass ratio between exhaust gases to fresh reactants, exceeds 30\%. As is shown in Fig. 6, however, stable combustion domain appears for high rates of exhaust gas recycling if combustion air is preheated higher than auto-ignition temperature. Actually, very diluted air with burned gases, whose oxygen concentration as low as $3 \%$ can sustain combustion when it is preheated up to $1200 \mathrm{~K}$.

The influences of preheat temperature and oxygen content in diluted combustion air on flame temperature are shown in Fig. 7, where temperature profile in laminar diffusion flames between fuel of ambient tem perature and preheated air or its dilution with combustion products in counter flow configuration are depicted. The peak temperature in flame increases with preheat of combustion air (Fig. 7(a)), although the rise in peak temperature becomes small due to dissociation of combustion products in high temperature range. The variation of peak temperature and the temperature rise due to combustion are clearly demonstrated in Fig. 7 (b) when the diluted air temperature was kept $1400 \mathrm{~K}$. In spite of high preheat; the maximum flame temperature in case of $5 \%$ oxygen is decreased far below than the one for pure air of ambient temperature.

The influence of heat and gas recycling on flame temperature are discussed in Ref.(23). Combustion with highly preheated air and high recycling rate of burned gas generates relatively low maximum flame temperature. We can understand that the stoichiometric flame temperature in much diluted air, where mass fraction of oxygen is far below the value in normal atmospheric air, is not as high as we usually expect.

This is the key for highly preheated air combustion when it is applied to practical combustion systems. Keeping the global equivalence ratio constant,

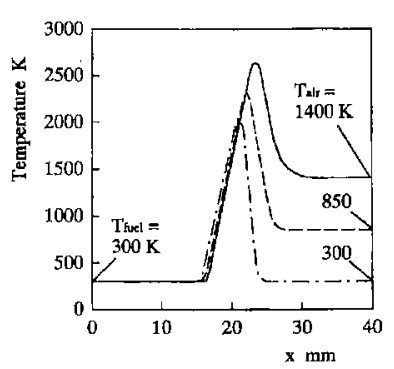

(a) Influence of air preheat

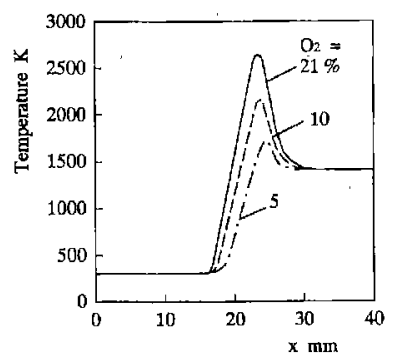

(b) Influence of oxygen content
Fig. 7 Comparison of maximum flame temperature in counter-flow diffusion flames the flame temperature in the furnace can be varied or regulated by combining the air preheat temperature and the recycling rate of burned gases which can be induced by the high momentum ejection of combustion air as well as the furnace configuration.

\section{Advanced Low $\mathrm{NO}_{x}$ Technolygy}

The observation above showed us that the flame temperature of non-premixed flame is strongly dependent on the mixing process of combustion air with burned gases, namely the dilution of air with burned products. Accordingly, it is possible to generate lower temperature flames by use of highly preheated air mixed with high rate of burned gas recirculation than that in ordinary flames burning with atmospheric air.

Intense mixing of combustion air with plenty of burned gas in the furnace, which is brought by high momentum ejection of combustion air, yields distributed reactions and lowers flame temperatures. This combustion regime in low oxygen concentration can be sustained only by the supply of highly preheated air. If air of ambient temperature is supplied, the flame will be extinguished instantly. Therefore, in addition to the use of highly preheated air, the intense mixing of the air with plenty of burned gas before combustion is essential for low flame temperatures, hence low nitric oxide emission.

We can understand its importance in generating low oxygen diluted air before combustion. This kind of combustion in low concentration of oxygen can be sustained only by a supply of highly preheated air, because the temperature of the diluted air with high rate of burned gas recirculation should be higher than the auto-ignition temperature shown in Fig. 6. If atmospheric air is used for this type of low oxygen combustion, combustion never occurs in the furnace. Accordingly, advanced low $\mathrm{NO}_{x}$ technology becomes possible if we use highly preheated air whose temperature is high enough for auto-ignition when it is diluted with recirculated burned gases.

The schematic concept of highly preheated air combustion is illustrated in Fig. 8 comparing with that of ordinary combustion. Typically highly preheated air combustion exhibits invisible flames or flameless ${ }^{(24)}$. From the experimental observations, this type of combustion usually shows moderate average temperature rise in spite of the perfect combustion of the same fuel flow rates. Therefore, the combustion is considered to occur in widely distributed reaction zones, where the local heat release is also distributed generating small temperature fluctuations.

\section{Radiative Heat Transfer}

A large volume reaction zone recognized by a 


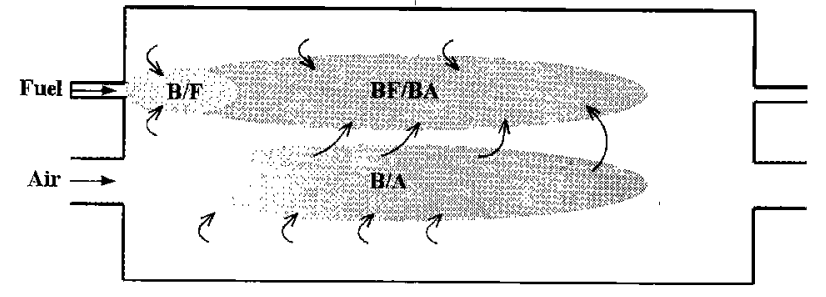

(a) Conventional furnace combustion

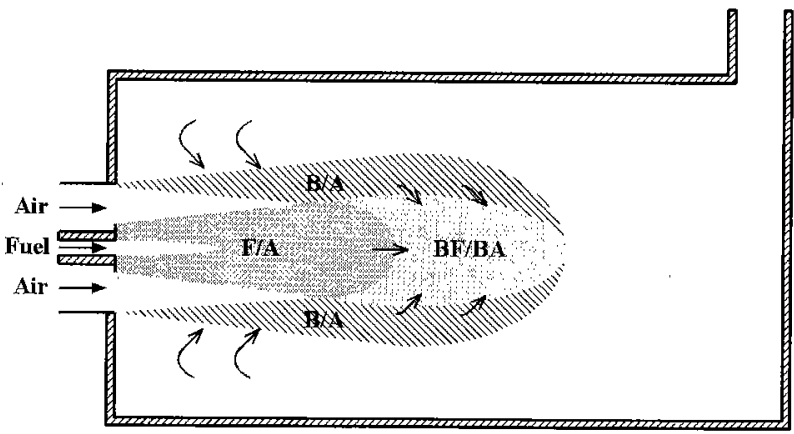

(b) Advanced low $\mathrm{NO}_{x}$ regenerative furnace

Fig. 8 Concept of mixing and combustion in furnaces

mild temperature rise with low luminosity is a typical feature of highly preheated air combustion that is definitely different from ordinary combustion burning with luminous flames. Nevertheless, heating furnaces run by highly preheated air show efficient heating ability. When we discuss the heat transfer in furnaces, we must take into account radiation characteristics of gas and solid as well as temperature distribution.

Heating material of high emissivity placed in high temperature surroundings act as an absorber for short wavelength and a weak reflector for long wavelength.

Regarding energy exchange between gas and walls, walls having high absorptivity in short wavelength mostly absorb the energy radiated from combustion gas. Since gas is considered transparent medium in long wavelengths except band absorption spectra of $\mathrm{H}_{2} \mathrm{O}$ or $\mathrm{CO}_{2}$, the net exchange of radiant energy between walls balances each other because of the small deviation in wall temperature. Therefore, radiant energy is transferred from walls to heating materials according to their respective temperature, since the both have high emissivity at long wavelength. These radiation characteristics of gas and solid in terms of wavelength produce a desirable function of wavelength conversion in the radiative heat transfer network in furnaces.

The mechanism of the wavelength conversion in the vicinity of $1500 \mathrm{~K}$ is schematically shown in Fig. 9. The radiation energy from combustion gas is emitted mainly from $\mathrm{CO}_{2}$ and $\mathrm{H}_{2} \mathrm{O}$ and sometimes from hydrocarbon contents, such as $\mathrm{CH}_{4}$, as band emissions

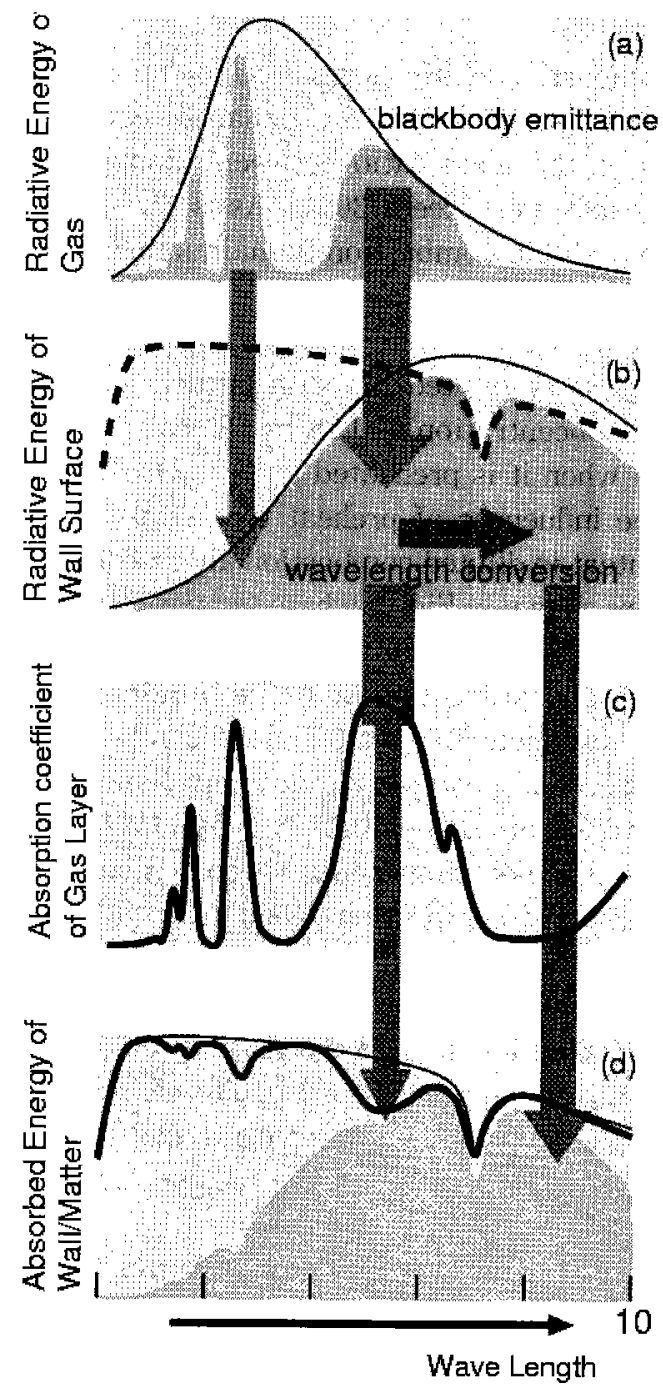

Fig. 9 Radiation energy exchange by wavelength conversion $^{(29)}$

usually distributed in the wavelength range over $2 \mu \mathrm{m}$, as shown in (a). Then, walls having the absorptivity indicated by the dotted line in (b) absorb it, and it is converted into heat recognized as a temperature rise. The product of its emissivity and the emissive power of black body of the same temperature as shown in (b) determine the radiant intensity from the wall. Though combustion gas absorbs a part of radiation emitted from walls selectively as shown in (c), most of the radiation energy converted into different wavelengths reaches the opposite wall as shown in (d). Since the radiation energy absorbed in the combustion gas is as small as 2 to $5 \%$ at most in the example case, radiative heat transfer between walls dominates the heat exchange in the furnace.

The energy radiated in a short wavelength from flame is scarcely trapped by almost transparent combustion gas due of its low absorptivity. Once it reaches onto an opposing wall, it is converted into 
radiation having a spectrum of wavelength, and the radiation energy is retained in the furnace and used for heating of materials.

\section{New Heating Process}

In order to achieve high thermal efficiency as well as low nitric oxide emission, the combustion of a pair of regenerative burners and the high rate of recycling of burned gas in the furnace has been applied in a high performance industrial furnace run by highly preheated air. Accordingly, the features of the technology, not only the high frequency alternating flow operation of a pair of burners but also the distributed combustion reactions in low oxygen circumstances, contribute to produce uniform temperature distribution in the furnace.

Practically, a uniform distribution across the process is produced in the case where a lot of pair burners are installed along a heating process as shown in Fig. 10. Since the existence of local high temperature in the process, which is often seen in typical heating processes may cause the damage or non-uniform heating of material. The cross sectional uniform heating performed in the new process allows higher average temperature as a result of eliminating the local over-heating, hence the higher thermal efficiency of the process as well as the high quality of products due to uniform thermal treatment can be achieved.

In the direction of material flow of the new heating process, the temperature in each zone of the process can be controlled independently to produce an appropriate heating pattern in accordance with the temperature change of the heated material. The flexibility of the heating pattern control, being called

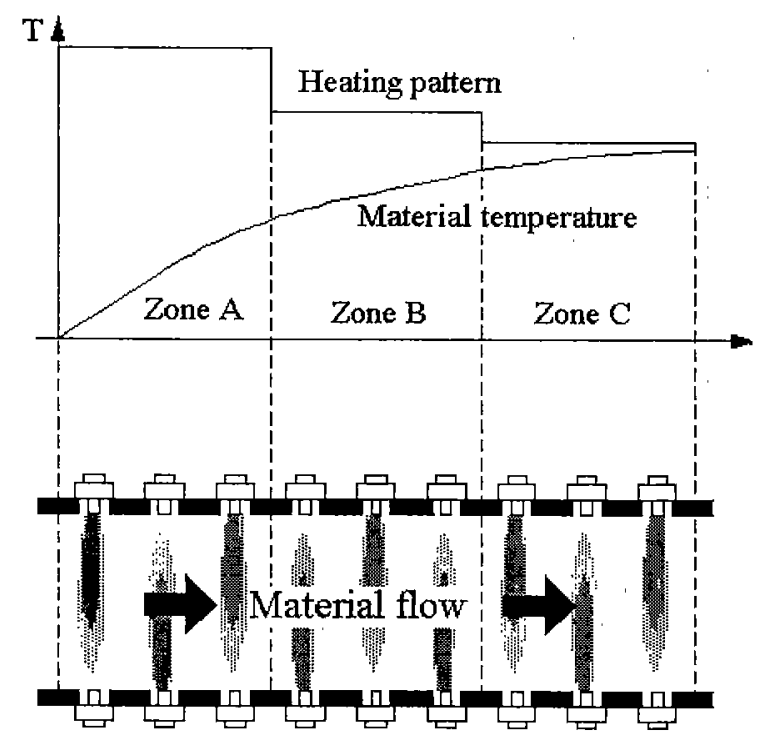

Fig. 10 High quality heating process using highfrequency regenerative burners ${ }^{(21)}$ as free scheduling heating control, brought by the cross-firing of a pair of regenerative burners also contributes to fuel saving and downsizing. Actually, it is estimated that more than $30 \%$ of energy saving and $20 \%$ of downsizing will be possible in a prototype reheating furnace of $285 \mathrm{t} / \mathrm{h}$ capacity. If this technology is applied to all of the similar furnaces in Japan, it is reported approximately 5 percent of the national total energy consumption will be saved ${ }^{(22)}$.

\section{Application to Varaiety of Fields}

In the developing process of high performance industrial furnace, highly preheated air combustion and its practical application as an advanced low $\mathrm{NO}_{x}$ technology were carried out successfully ${ }^{(25)-(27)}$. However, the applied area was limited so far within high temperature furnaces where this technology can be easily applied. Therefore, it is worth trying to apply this attractive technology to other fields, such as boilers, gas turbines, and IC engines.

Here is a typical view insisting that it has no advantage to adopt regenerative burners in such a heating system emitting low temperature exhaust like a boiler, because neither large increase of thermal efficiency nor sufficient preheating of combustion air can be expected by regeneration. It is quite reasonable from an economical point of view. However, if nitric oxide emission can be reduced dramatically without any decrease in thermal efficiency, it is worth developing as a future technology from an ecological point of view.

Suppose heat utilization processes in a boiler, starting from the heat release due to combustion to the exhaust, the temperature varies typically from approximately $1800 \mathrm{~K}$ down to $400 \mathrm{~K}$. Namely, there is always the appropriate temperature on the way high enough for highly preheated air combustion, although the final exhaust temperature is insufficient for regenerative combustion. Therefore, we divide the burned gas flow into two parts at a high temperature level sufficient for highly preheated air combustion and utilize one part for the heat regeneration system and the other part for the boiler. Since the stored heat in the regenerator is recycled into the boiler in the following cycle, there is no decline in thermal efficiency as far as a change of heat loss is taken into account. The point is the exhaust gas temperature leaving the regenerator. If the temperature is lower than the exhaust temperature of boiler, it is no problem. In case of the higher temperature, a heat recovery device like a water-heater should be added to the system. Thus in Fig. 11, we can demonstrate an example of advanced low $\mathrm{NO}_{x}$ boiler having the same thermal efficiency as the existing types. 


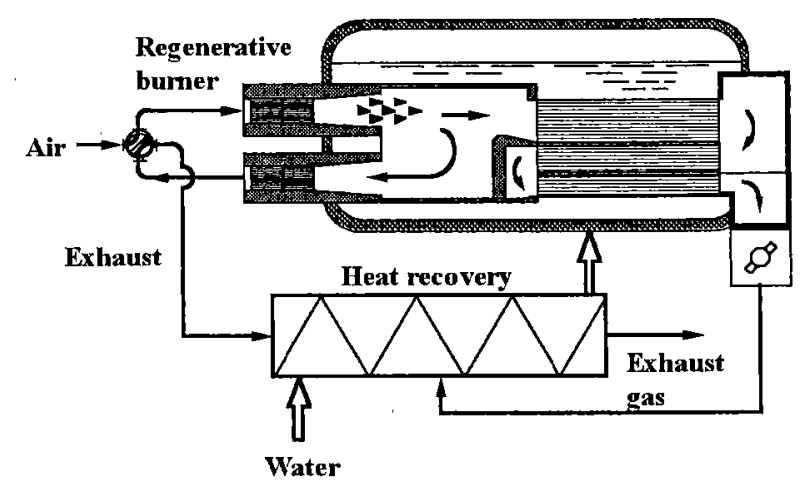

Fig. 11 Boiler with regenerative burner system (schematic) (28)

There is a variety of combustion or heating systems like a boiler and a tube heater whose exhaust gas temperature is lower than the auto-ignition temperature of fuel. Nevertheless, it is possible to design a heat regenerative combustion associated with highly preheated air as demonstrated above. We believe that it is worth making an effort to apply the concept of highly preheated air combustion to new fields, such as gas turbines and diesel engines, where combustion methods are quite different from those in industrial furnaces.

\section{Conclusions}

In recent advances in combustion technology the development of high performance regenerative furnace is the most epoch-making technology. The high frequency alternating flow-type regenerator used in the system has been proven quite effective in achieving high degree of energy saving. It keeps exhaust gas temperature sufficiently low and raises fresh air temperature up to almost furnace exit temperature as if a thermal dam were built at the furnace exit. Another attractive characteristic of the regenerative furnace is extremely low nitric oxide emission notwithstanding high preheat of combustion air. It has been clarified that combustion can take place in an extremely low concentration of oxygen if combustion air is preheated sufficiently higher than the auto-ignition temperature of fuel. The low oxygen content in oxidizer is brought by a mixing control of preheated combustion air with burned gas in the furnace. Dilution makes oxygen content of the oxidizer low, which decreases temperature fluctuations in flames as well as the mean temperature, hence low nitric oxides emission.

Since it seems possible to apply the concept to new fields, further efforts of practical application of this technology to other combustion devices and systems are hopeful in the future

\section{Aknowledgements}

The author gratefully acknowledges the support by NEDO and all the members participated in the national project, High Performance Industrial Furnaces Development.

\section{References}

(1) Weinberg, F.J., Advanced Combustion Methods, (1986), Academic Press, New York.

(2) Weinberg, F.J., Combust. Sci. Technol., Vol. 121 (1996), pp. 3-22.

(3) Lloyed, S.A. and Weinberg, F.J., Nature, Vol. 251 (1974), pp. 47-49, ibid., Vol. 257 (1975), pp. 367370.

(4) Hardesty, D.R. and Weinberg, F.J., Combust. Sci. Technol., Vol. 8 (1974), pp. 201-214.

(5) Takeno, T., Sato, K. and Hase, K., Proc. Combustion Institute, Vol. 18 (1982), pp. 465-471.

(6) Babkin, V.S., Korzhavin, A.A. and Bunev, V.A., Combust. Flame, Vol. 87 (1991), pp. 182-190.

( 7 ) Zhdanok, S., Kennedy, L.A. and Koester, G., Combust. Flame, Vol. 100 (1995), pp. 221-231.

(8) Hanamura, K., Echigo, R. and Zhdanok, S.A., Int. J. Heat and Mass Trans., Vol. 36 (1993), pp. 32013209.

(9) Hanamura, K., Adachi, M. and Echigo, R., 4th Int. Conf. on Technologies and Combustion for Clean Environment, Lisbon, (1997).

(10) Echigo, R., Kurusu, M., Ichimiya, K. and Yoshizawa, Y., ASME-JSME Thermal Eng. Joint Conf., Vol. 4 (1983), pp. 99-103.

(11) Niioka, T., ASME-JSME Thermal Eng. Joint Conf., (1999), pp. 1-6.

(12) Masters, J., Webb, R.J. and Davies, R.M., J. Institute Energy, Vol. 52 (1979), pp. 196-204.

(13) Cornforth, J.R., Combustion Engineering and Gas Utilization, British Gas, 3rd edition, (1992).

(14) Sugiyama, T., Nagata, T. and Nakamachi, I., 9th IFRF Members Conf., (1989).

(15) Matsumoto, M., Nakamachi, I., Yasuoka, S., Saiki, N. and Koizumi, T., 11th IFRF Members Conf., (1995).

(16) Dearden, L.M., Massingham, J.D., Pourkashanian, M., Wild, P.N., Williams, A. and Yap, L.T., J. Institute Energy, Vol. 69 (1996), pp. 23-30.

(17) Flamme, M. and Kremer, H., Int. Gas Research Conf., Orlando, (1992).

(18) Flamme, M., 4th Int. Conf. on Technologies and Combustion for a Clean Environment, Lisbon, (1997).

(19) Nishimura, M., Suzuki, T., Nakanishi, R. and Kitamura, R., Energy Conversion and Management, Vol. 38 (1997), pp. 1353-1363.

(20) Hasegawa, T. and Hoshino, T., JFRC Annual Conf., (1992).

(21) Katsuki, M. and Hasegawa, T., Proc. Combustion Institute, Vol. 27 (1998), pp. 3135-3146.

(22) National Project Report, Japan Industrial Fur- 
nace Manufacturers Association, (1997).

(23) Hasegawa, T., Tanaka, R. and Kishimoto, K., AFRC/JFRC Int. Conf., Paper 9C, (1994).

(24) Wünning, J.A. and Wünning, J.G., Progress in Energy and Combustion Science, Vol. 29 (1997), pp. 81-94.

(25) Hasegawa, T., Tanaka, R. and Niioka, T., The First Asia-Pacific Conf. on Combust., (1997), pp. 290-293.

(26) Sato, J., The First Asia-Pacific Conf. on Com- bust., (1997), pp. 286-289.

(27) Suzukawa, Y., Sugiyama, Y., Hino, Y., Ishioka, M. and Mori, I., Energy Conversion and Management, Vol. 38 (1997), pp. 1061-1071.

(28) Choi, G.M. and Katsuki, M., Energy Conversion and Management, Vol. 42 (2001), pp.630-652.

(29) Tsuji, H., Gupta, A.K., Hasegawa, T., Katsuki, M., Kishimoto, K. and Morita, M., High Temperature Air Combustion, (2002), CRC Press, New York. 